\title{
Water-soluble fullerene (C60) inhibits the development of arthritis in the rat model of arthritis
}

This article was published in the following Dove Press journal:

International Journal of Nanomedicine

16 October 2009

Number of times this article has been viewed

\author{
Kazuo Yudoh' \\ Rie Karasawa' \\ Kayo Masuko² \\ Tomohiro Kato ${ }^{2}$ \\ 'Institute of Medical Science, \\ ${ }^{2}$ Department of Biochemistry, \\ St. Marianna University School \\ of Medicine, Kawasaki, Japan
}

Correspondence: Kazuo Yudoh Department of Frontier Medicine, St. Marianna University School of Medicine 2-16-I Sugao, Miyamae-ku, Kawasaki City 216-85I2, Japan Email yudo@marianna-u.ac.jp
Abstract: Recently, it has been demonstrated that oxygen free radicals have an important role as a signaling messenger in the development of inflammation and osteoclastogenesis, suggesting the implication of oxygen free radicals in the pathogenesis of arthritis. The aim of this study was to examine the potential of a strong free-radical scavenger, water-soluble fullerene (C60), as a protective agent against synovitis in arthritis, both in vitro and in vivo. In the presence or absence of C60 $(0.1,1.0,10.0 \mu \mathrm{M})$, human synovial fibroblasts, synovial infiltrating lymphocytes or macrophages were incubated with tumor necrosis factor- $\alpha$ (TNF- $\alpha$ ) $(10.0 \mathrm{ng} / \mathrm{mL})$, and the production of proinflammatory cytokines by the individual cells were analyzed. C60 significantly suppressed the TNF- $\alpha$-induced production of proinflammatory cytokines in synovial fibroblasts, synovial infiltrating lymphocytes and macrophages in vitro. Adjuvant induced arthritic rats were used as an animal model of arthritis. Rats were divided into two subgroups: control and treatment with $\mathrm{C} 60$ at $10.0 \mu \mathrm{M}$. The left ankle joint was injected intraarticularly with water-soluble C60 $(20 \mu 1)$ in the C60-treated group, while, as a control, the left ankle joint in the control rats received phosphate-buffered saline $(20 \mu \mathrm{l})$, once weekly for eight weeks. Ankle joint tissues were prepared for histological analysis. In adjuvant-induced arthritic rats, intra-articular treatment with $\mathrm{C} 60$ in vivo reduced synovitis and alleviated bone resorption and destruction in the joints, while control ankle joints showed progression of synovitis and joint destruction with time. These findings indicate that $\mathrm{C} 60$ is a potential therapeutic agent for inhibition of arthritis.

Keywords: fullerene, inflammation, arthritis, synovitis, bone resorption

\section{Introduction}

Rheumatoid arthritis (RA) is a chronic inflammatory disease characterized by synovitis involving synovial hyperplasia with neoangiogenesis and infiltration of lymphocytes and macrophages into the synovial tissue. ${ }^{1}$ Synovial infiltrating inflammatory cells, which produce various inflammatory cytokines and growth factors, are intimately involved in a variety of symptoms of RA. ${ }^{2}$ It is observed in the joint tissues of RA patients that the synovial hyperplasia erodes and destroys the bone and cartilage. ${ }^{1-3}$

In the management of RA, antitumor necrosis factor (anti-TNF- $\alpha$ ) agents are becoming more widely available and offer the rapid onset of effective treatment, although there still remains no adequate explanation for some patients' poor response to this class of agents. ${ }^{4-7}$ Even an excellent anti-RA drug cannot be effective for all patients; there are always responders and nonresponders to an individual antirheumatic drug. ${ }^{8,9}$ Furthermore, long-term administration of a drug induces tolerance, that is, reduction of drug effectiveness, to itself even in initial responders, who have 
to increase its dosage or change drugs. Drug administration is also sometimes restricted due to a patient suffering complications. ${ }^{4-6}$ In order to treat nonresponders or patients who cannot take certain drugs because of complications, the development of a novel anti-RA drug is still much needed. Research into newer pharmacological therapies is ongoing with multiple compounds in development. ${ }^{10}$

Proinflammatory cytokines (TNF- $\alpha$, interleukin-1 [IL-1], IL-6, IL-17, etc.) produced mainly by macrophages are intimately involved in the pathogenesis of RA. ${ }^{1-3,10}$ It has already been demonstrated that reactive oxygen species (ROS) are increasingly produced by inflammatory cells in response to stimulation by proinflammatory cytokines such as TNF- $\alpha$, IL-1, IL-6, and IL-17 and play an important role as a messenger of the intracellular signaling pathway (nuclear factor-kappaB [NFkB], P38, phosphatidylinositol-3 [PI3] kinase), suggesting that ROS in turn activates inflammatory cells that have a part in the progression of inflammation. ${ }^{11-17}$ These findings indicate that ROS has an important role in the generation of inflammation. Targeting of ROS could have a therapeutic value as a strategy to reduce the development of inflammation.

In the joint of patients with RA, osteoclastic hyperresorption is accelerated as the disease progresses. The osteoimmunology, shared mechanisms, and crosstalk between the immune system and bone metabolism, are closely involved in the pathogenesis of RA. ${ }^{18-21}$ Induction of osteoclast differentiation from precursor cells is known to be linked by receptor activator of NFKB (RANK)-RANK ligand (RANKL) signals. ${ }^{20}$ RANKL is expressed by synovial fibroblasts, activated $\mathrm{T}$ cells and macrophages as well as osteoblasts and the expression is induced by proinflammatory cytokines including IL-1, IL-6, IL-17, and TNF- $\alpha$, which are implicated in the pathogenesis of RA. ${ }^{20-22}$ These findings suggest that the bone metabolism is closely involved with the inflammation in a variety of diseases.

It has been already reported that several of the intracellular signals essential for activation of inflammatory process, including NFKB, c-Jun amino-terminal kinase, PI3-kinase, and p38 MAPK, are sensitive to ROS. ${ }^{23-25}$ It has been demonstrated that NFKB is a target for cellular activation by ROS, ${ }^{25,26}$ and that antioxidants suppress NFKB activation in osteoclasts. ${ }^{27-29}$ Recent studies clearly have revealed that ROS mediates the inflammation and immune response. ${ }^{25-28}$ Thus, targeting of ROS could, therefore, have a distinct therapeutic value as a strategy to prevent the inflammation, such as synovitis, in arthritis.

Fullerene (C60) is composed of spherical carbon molecules with a unique cage structure. ${ }^{30,31}$ This compound has a high reactivity with oxygen free radicals and potential activity as a strong free radical scavenger. ${ }^{32}$ It has been reported that the antioxidant level of C60 is several hundred-fold higher than that of other antioxidants. ${ }^{32}$ Recently, C60 derivatives have shown some remarkable biologic properties such as neural apoptosis, ${ }^{33}$ promotion of chondrogenesis, ${ }^{34}$ and protection of skin keratinocytes from ROS-induced cell death after ultraviolet stress. ${ }^{35}$ We have already demonstrated that watersoluble C60 fullerene, a strong free-radical scavenger, can function as a protective agent against catabolic stress-induced degeneration of articular cartilage in a model of osteoarthritis in vitro and in vivo. ${ }^{36}$ Water-soluble C60 significantly reduced articular cartilage degeneration in the osteoarthritis rabbit model. These findings suggest that C60 has the potential to protect against oxygen free radical-induced pathological features in a variety of diseases ${ }^{37}$ Exploitation of C60 could lead to the development of novel therapeutic strategies in the prevention of both inflammation/synovitis and osteoclastic hyper-resorption in RA.

In the present study, we investigated the influence of water-soluble $\mathrm{C} 60$ on generation of inflammation in order to explore any therapeutic or protective effect of $\mathrm{C} 60$ on the synovitis in RA. We confirmed the suppressive effects of $\mathrm{C} 60$ on proinflammatory cytokine production from synovial inflammation-related cells. Our results indicated that intraarticular treatment with C60 significantly reduced synovitis and joint destruction in adjuvant-induced arthritic rats. These findings demonstrate that C60 has suppressive effects on synovitis and the resultant joint destruction in arthritis, suggesting that it could be useful for prevention and treatment of arthritis.

\section{Patients and methods}

\section{Cell culture}

Synovial fibroblasts, synovial infiltrating lymphocytes and macrophages isolated from synovial tissue in patients with RA were used in this study. All samples were obtained after informed consent, and this study was approved by the local institutional ethics committee. Cell viability was determined by trypan blue exclusion.

\section{Preparation of synovial fibroblasts}

Fresh synovial samples were obtained at the time of arthroplastic knee surgery or knee joint synovectomy performed on eight female patients with RA (age range 50-78 years).

After careful removal of the adipose tissue, the synovial samples were cut into small pieces and minced, then incubated in liquid low-glucose Dulbecco's modified Eagle's 
medium (DMEM; Sigma, St. Louis, MO, USA) containing collagenase (Sigma) at $1.0 \mathrm{mg} / \mathrm{ml}$ at $37{ }^{\circ} \mathrm{C}$ overnight, after which the synovial fibroblasts were isolated for culture. After washing the cells with phosphate-buffered saline (PBS; Nissui Co., Tokyo, Japan), the cells were cultured in DMEM containing 10\% heat-inactivated fetal calf serum (FCS; Wako Pure industries, Tokyo, Japan), 2 mM 1-glutamine, 25 mM HEPES (2-[4-(2-hydroxyethyl)-1piperazinyl], and penicillin and streptomycin at $100 \mathrm{units} / \mathrm{ml}$. The cells were incubated at $37^{\circ} \mathrm{C}$ in a humidified atmosphere of $5 \% \mathrm{CO}_{2}$ and $95 \%$ air. Cells were used from passage 2 to 5 , during which time they were a homogeneous population of fibroblast-like synoviocytes.

\section{Preparation of synovial infiltrating lymphocytes and macrophages}

Fresh synovial samples were obtained as described above. After careful removal of the adipose tissue, synovial samples were minced on tissue culture plates, digested with collagenase ( $1 \mathrm{mg} / \mathrm{ml})$ in RPMI-1640 (Gibco, New York, NY, USA) supplemented with $10 \% \mathrm{FCS}$, incubated for six hours at $37^{\circ} \mathrm{C}$, filtered through a $70-\mu \mathrm{m}$ nylon mesh, and centrifuged. The cell pellet was resuspended in RPMI-1640/10\% FCS at a density of $1 \times 10^{6}$ cells $/ \mathrm{ml}$, and seeded onto culture plates. After a sixhour incubation, nonadherent cells were harvested, and were used to isolate lymphocytes by Ficoll-Paque density gradient centrifugation. Adherent cells were harvested and enriched CD68 monocytes were purified by magnetic depletion of non-CD68 positive cells, using the MACS indirect magnetic labeling system according to the manufacturer's instructions (MACS; Miltenyi Biotec, Auburn, CA, USA). The cells were cultured in RPMI 1640 with $10 \% \mathrm{FCS}$ at $37^{\circ} \mathrm{C}$ in a humidified atmosphere of $5 \% \mathrm{CO}_{2}$ and $95 \%$ air.

\section{Effect of $\mathrm{C} 60$ on production of proinflammatory cytokines by synovial fibroblasts, infiltrating lymphocytes and macrophages}

Arthritis is an inflammatory disease where inflammation occurs mainly in the synovium of the joint. We studied the direct action of C60 on synovial infiltrating lymphocytes and macrophages as well as synovial fibroblasts from the perspective of production of proinflammatory cytokines by these cells. Water-soluble C60 was purchased from Vitamin C60 Bio Research (Tokyo, Japan). ${ }^{38,39}$

To examine the effect of C60 on the production of cytokines by synovial fibroblasts, synovial infiltrating lymphocytes and macrophages, the levels of proinflammatory cytokines produced by individual cells were analyzed by an enzyme-linked immunosorbent assay (ELISA) and Western blot analysis. A single cell suspension was seeded on 24-well culture plates at $5 \times 105$ cells/well. The cells were incubated with C60 in the presence or absence of TNF- $\alpha(10.0 \mathrm{ng} / \mathrm{ml})$ at $37^{\circ} \mathrm{C}$ in a humidified atmosphere of $5 \% \mathrm{CO}_{2}$ and $95 \%$ air. The concentration of $\mathrm{C} 60$ was $0.1,1.0$, or $10.0 \mu \mathrm{M}$. After a 24 -hour incubation, the culture medium and cells were collected for ELISA and Western blot analysis, respectively.

The levels of proinflammatory cytokines, TNF- $\alpha$ and IL-1 $\beta$ in cell cultures were measured using an ELISA kit (ELISAs for TNF- $\alpha$ from Amersham Biosciences, Buckinghamshire, UK; IL-1 $\beta$ from R\&D Systems, Minneapolis, MN, USA) in accordance with the manufacturer's protocol. Data from four independent experiments were analyzed.

\section{Efficacy of $\mathrm{C} 60$ in animal models of arthritis}

We investigated whether $\mathrm{C} 60$ had any suppressive effects on arthritis (synovitis and joint destruction) using a rat arthritis model. Eight-week-old female Sprague-Dawley rats were obtained from Charles River Laboratories Japan (Tokyo, Japan). Adjuvant-induced arthritic rats were created as described in a previous report. ${ }^{40}$ To illustrate the pathology of RA, many models have been made to mimic the human RA process, among which adjuvant-induced arthritis model was most widely used. Indeed, the adjuvant-induced arthritis model has many morphological features similar to those of human RA, including patterns of synovitis, synovial hyperplasia, neoangiogenesis and infiltration of inflammatory cells into the synovial tissue, pannus formation, and erosion of the articular cartilage and bone. Moreover, the arthritis model shares many of the cytokines and biological factors in the synovium and cartilage with RA.

The ankle joints of 40 rats were assessed. After being once immunized to produce arthritis, the rats were divided into a control group ( $\mathrm{n}=20$ rats) and a C60-treated group $(\mathrm{n}=20$ rats). In the control group, the left ankle joint was treated with an intraarticular injection of $20.0 \mu 1$ PBS once per week for eight weeks, using a micro-needle syringe. In the C60-treated group, the left ankle joint was similarly treated with an intraarticular injection of $20.0 \mu \mathrm{l}$ C60 $(10.0 \mu \mathrm{M})$ once per week for eight weeks. The right knee joints were not treated in either group to be compared to the contralateral ankle joints for the observation of arthritis development and progress.

The levels of arthritis of the left ankle joints were evaluated according to the arthritis score ${ }^{41}$ every two weeks after immunization. After observation to assess the arthritis 
A

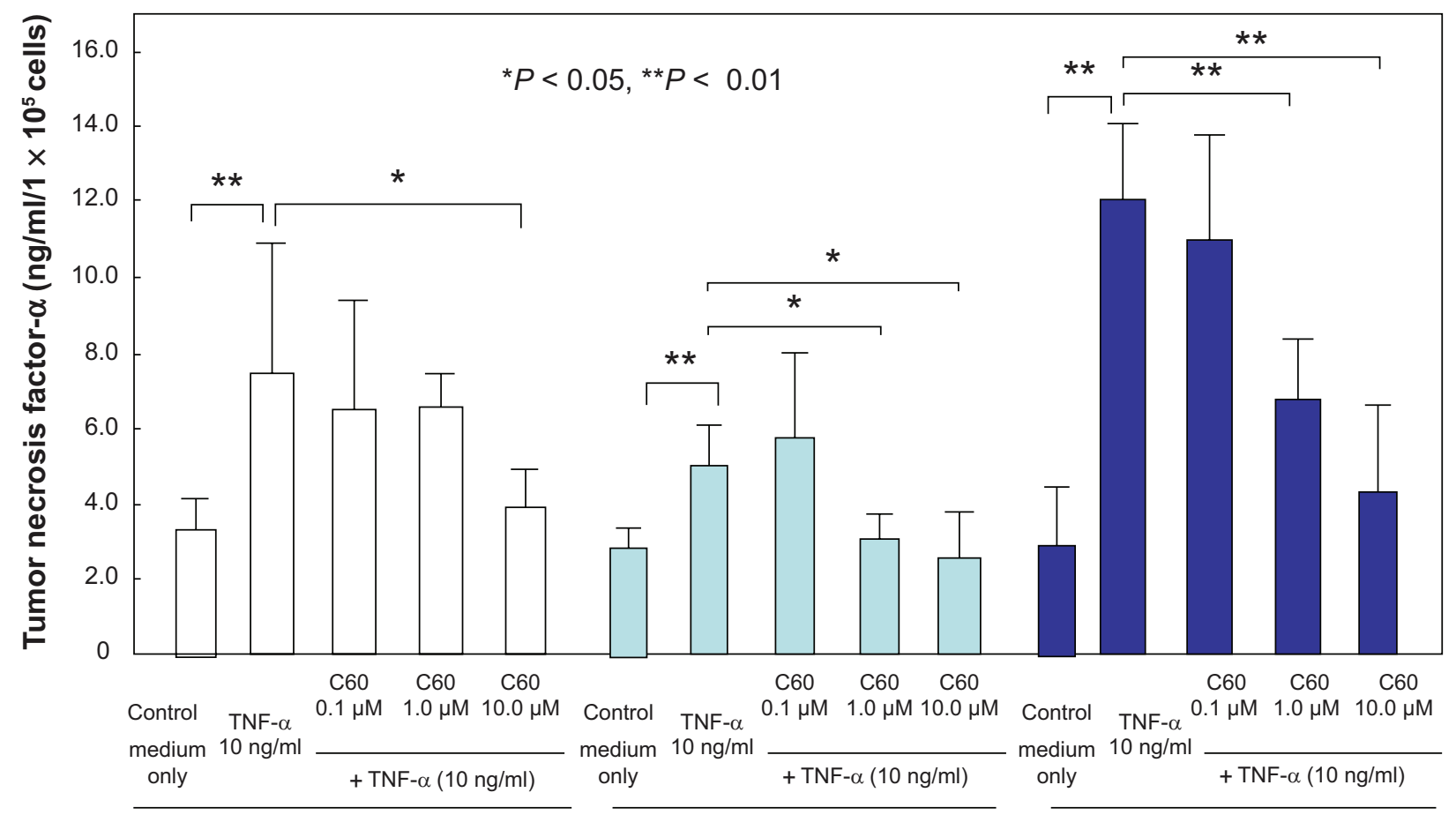

Synovial fibroblasts

Synovial infiltrating

lymphocytes

Synovial infiltrating macrophages

B

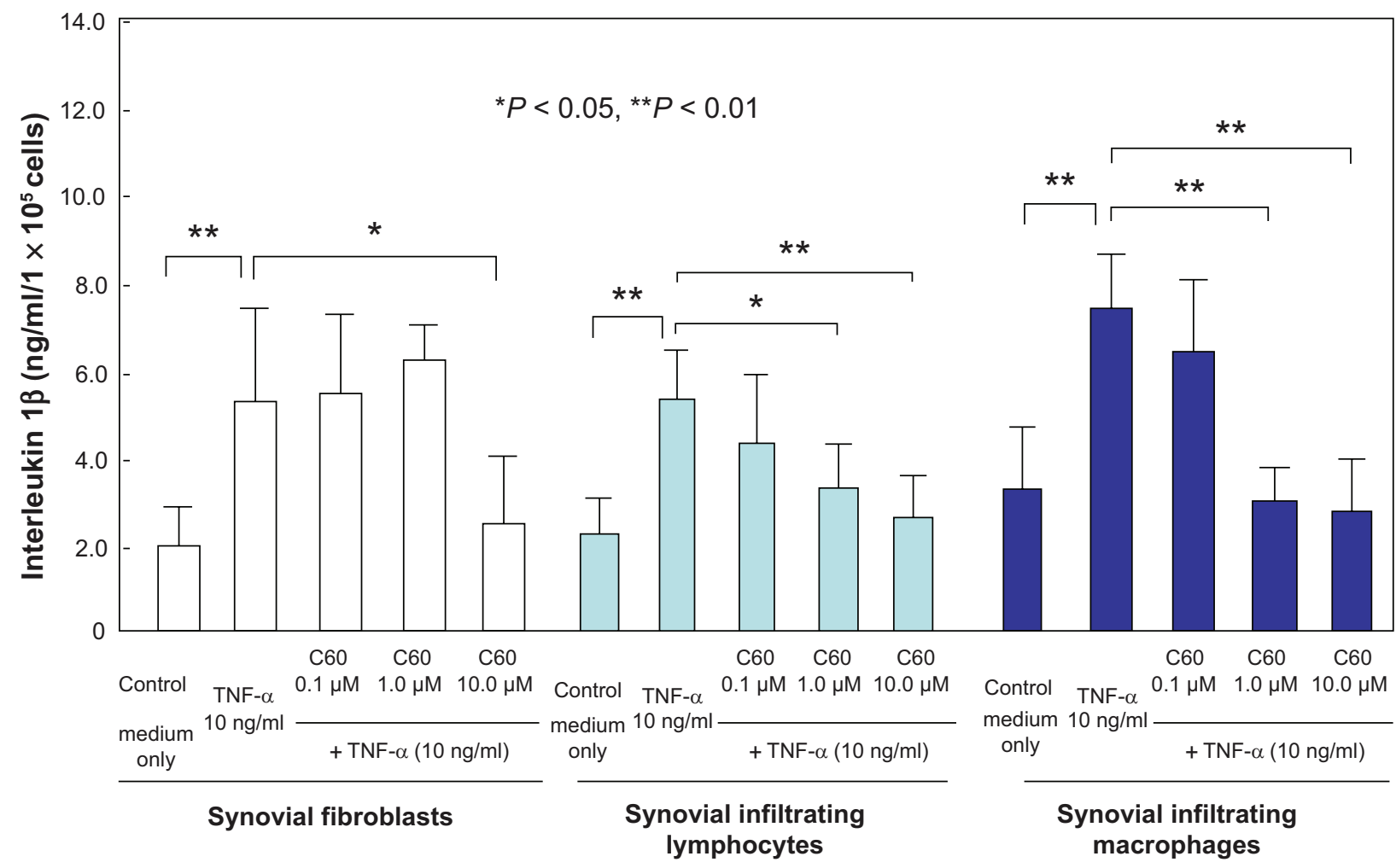

Figure I Effects of C60 on the production of tumor necrosis factor- $\alpha$ (TNF- $\alpha$ ) and interleukin-I $\beta$ (IL-I $\beta$ ) in synovial fibroblasts, synovial infiltrating lymphocytes and macrophages. Synovial fibroblasts, synovial infiltrating lymphocytes or macrophages were incubated with catabolic factor, TNF- $\alpha$ (I0.0 ng /ml) in the presence or absence of water-soluble C60 (0.I, I.0, or I0.0 $\mu \mathrm{M})$. After 24-hour incubation, the concentrations of proinflammatory cytokines were analyzed by ELISA (A:TNF- $\alpha$, B: IL-I $\beta$ ). TNF- $\alpha$ stimulated the production of TNF- $\alpha$ and IL-I $\beta$ by individual cells (*P $<0.05$, $* * P<0.0$ I compared to each control). C 60 significantly decreased the TNF- $\alpha$-induced excess production of TNF- $\alpha$ A) and IL-I $\beta$ B) from individual cells $(* P<0.05$, **P $<0.0$ I). Data from four independent experiments were analyzed. 
score, the rats were euthanized one, two, four, six, and eight weeks (four rats per time point) after immunization and both ankle joints were harvested. Bone and cartilage tissue blocks were prepared for histological analysis. All experiments were conducted with the approval of the University Animal Care and Use Committee.

Articular bone and cartilage samples were fixed for two days in $4 \%$ paraformaldehyde solution and then decalcified in $4 \%$ paraformaldehyde containing $0.85 \%$ sodium chloride and $10 \%$ acetic acid. Tissues were dehydrated through a series of ethanol solutions and infiltrated with xylene before being embedded in paraffin and cut into $6-\mu \mathrm{m}$ sections. Sections were deparaffinized through sequential immersion in xylene and a graded series of ethanol solutions in accordance with conventional procedures. The pathological tissue scores were calculated to histologically assess arthritis stages..$^{40-42}$ The mean damage score from the six samples from each animal was used to determine the mean \pm standard deviations for each group. Three independent observers assessed cartilage damage in a blinded manner.

\section{Statistical analysis}

Results are expressed as means \pm standard deviations. Data were analyzed by a nonparametric statistical analysis. A $P$ value $<0.05$ was considered statistically significant.

Student's $t$-test was used to assess the differences between C60-treated and control groups with respect to arthritis and histological parameters. When a statistically significant difference between the two groups was detected, analysis of variance (ANOVA) was used to adjust for the confounding effects of animals and observers.

\section{Results and discussion C60 decreases the production of proinflammatory cytokines in synovial inflammation-related cells}

TNF- $\alpha$ significantly stimulated the production of TNF- $\alpha$ (Figure 1A) and IL-1 $\beta$ (Figure 1B) by synovial fibroblasts, synovial infiltrating lymphocytes and infiltrating macrophages. In synovial fibroblasts, treatment with C60 $(10.0 \mu \mathrm{M})$ significantly inhibited the TNF- $\alpha$-induced excess production of TNF- $\alpha$ and IL- $1 \beta$ by the cells in synovial infiltrating lymphocytes and macrophages, $\mathrm{C} 60$ at 1.0 or $10.0 \mu \mathrm{M}$ significantly suppressed the accelerated production of both proinflammatory cytokines, TNF- $\alpha$ and IL- $1 \beta$, under catabolic stress, due to TNF- $\alpha$ at $10.0 \mathrm{ng} / \mathrm{ml}$ (Figures 1A, B). Our in vitro studies indicate that water-soluble $\mathrm{C} 60$ inhibits the

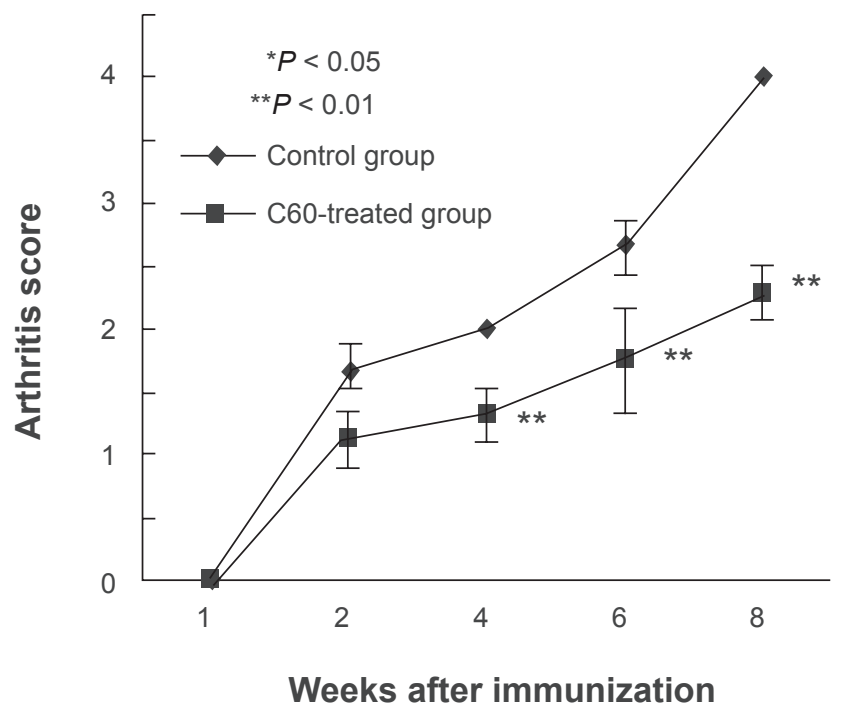

Figure 2 Intraarticular treatment of $\mathrm{C} 60$ inhibits the arthritis score in the arthritis model rats. In each rat after immunization, the left ankle joint was treated by intraarticular injection of the appropriate solution $(20.0 \mu \mathrm{l}$, Control: phosphate-buffered saline, $\mathrm{C} 60$-treated group: $10.0 \mu \mathrm{M} \mathrm{C} 60$ ) by micro-needle syringe once a week during the observation periods. In the control joint group, the arthritis score gradually increased with the advance of time. The score in the left ankles of rats that had been treated with $\mathrm{C} 60(10.0 \mu \mathrm{M})$ showed lower at four and eight weeks after immunization in contrast to the control ankle joints (four rats per time point).

following arthritis-related responses: the production of the proinflammatory cytokines, TNF- $\alpha$ and IL- $1 \beta$ from synovial fibroblasts, synovial infiltrating lymphocytes and macrophages. The results of our in vitro experiments suggest that C60 could have the potential to inhibit inflammatory synovitis in RA. The inhibitory effect of C60 on inflammation is based on the evidence that ROS is closely involved in the activation

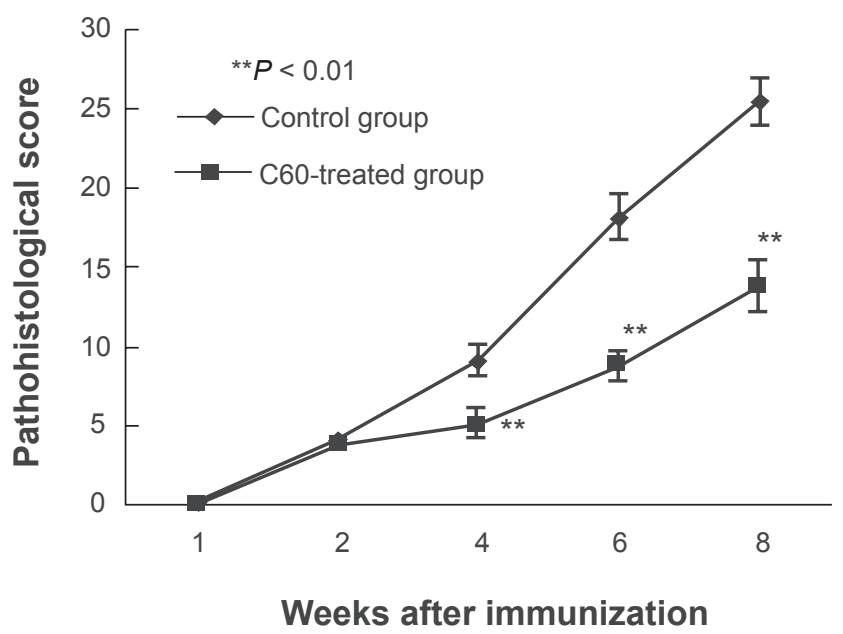

Figure 3 Intraarticular treatment of C60 inhibits the pathological score in the arthritis model rats. The degree of arthritis was histologically evaluated in each ankle joint sample (four rats per time point). Although infiltration of inflammatory cells into the synovium and joint destruction progressed with time in both control and $\mathrm{C} 60$-treated groups, the C60-treated group showed significantly lower pathological tissue scores at four weeks and later compared to the respective control group. 
A

\section{4 weeks}

Animal number $4 \mathrm{w}-1$
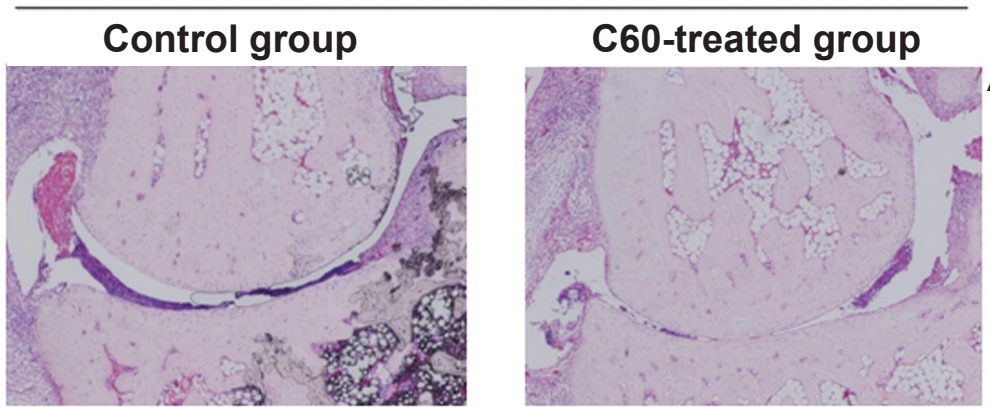

Animal number $4 w-5$

Animal number $4 w-2$
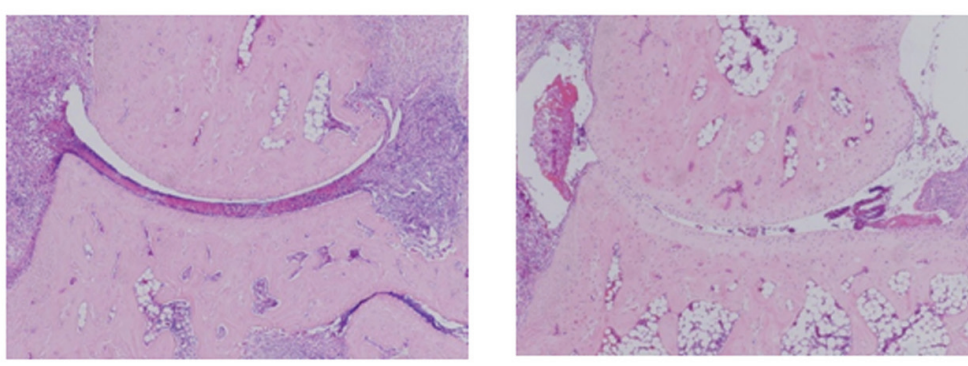

Animal number $4 w-6$

Animal number $4 \mathrm{w}-3$
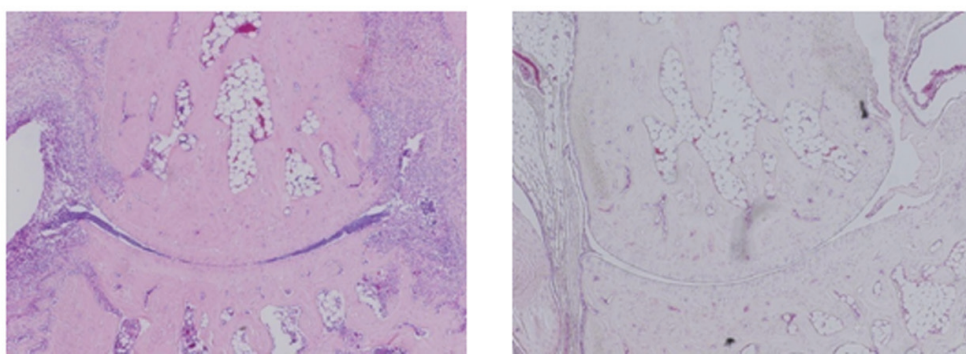

Animal number $4 w-7$

B

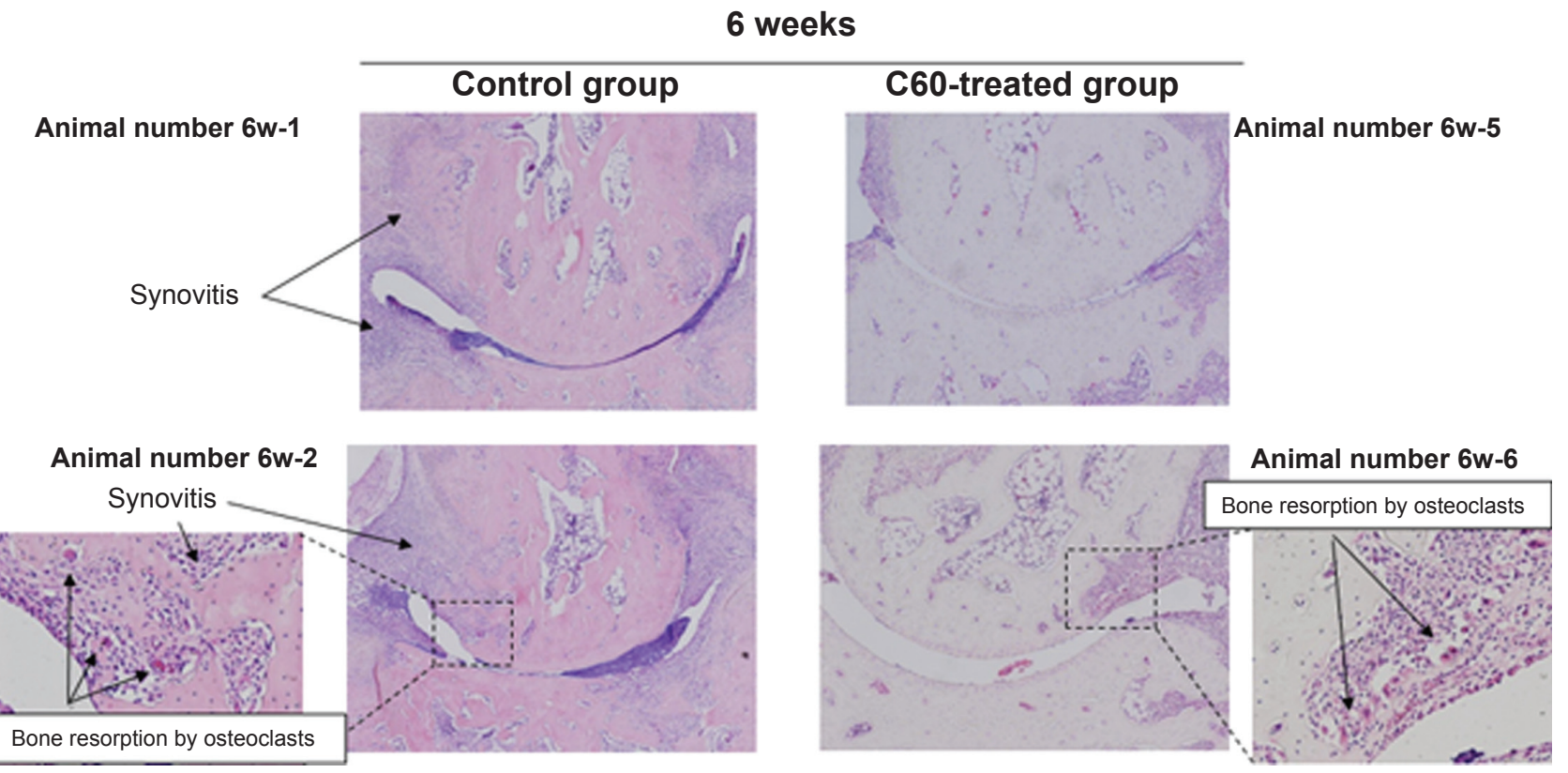


C

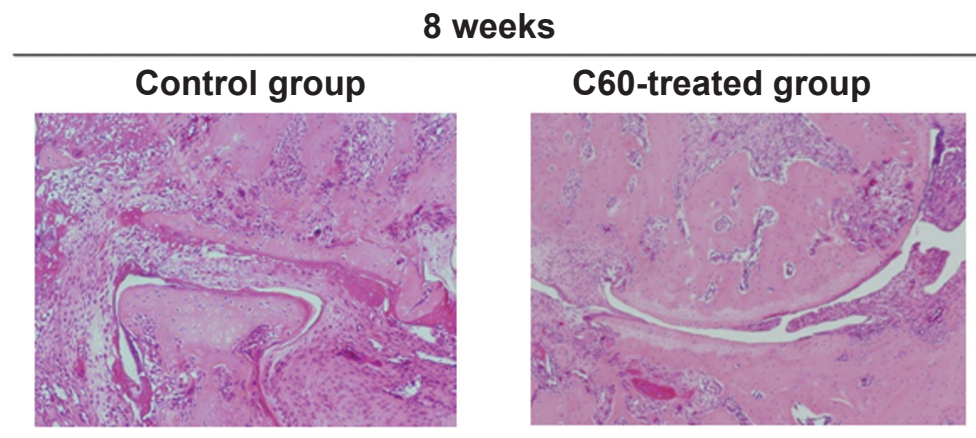

Animal number $8 w-5$

Animal number $8 w-1$
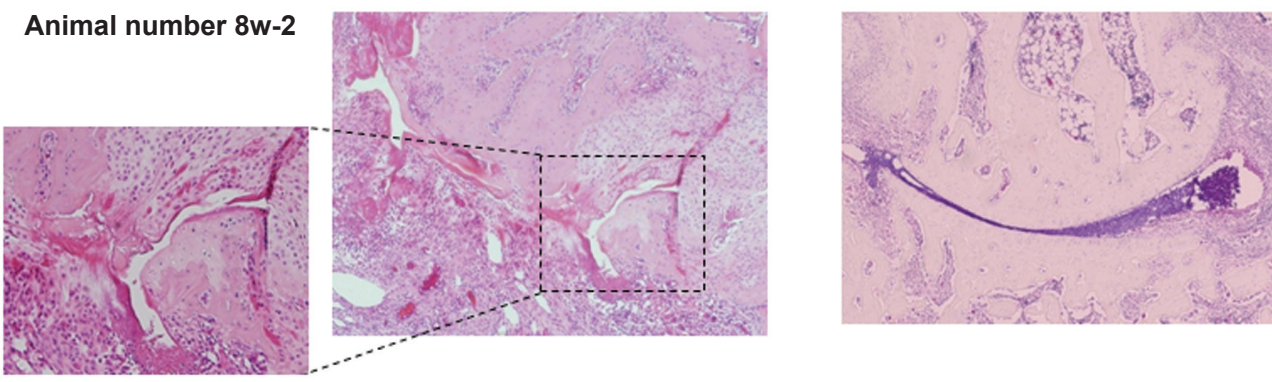

Animal number $8 w-6$
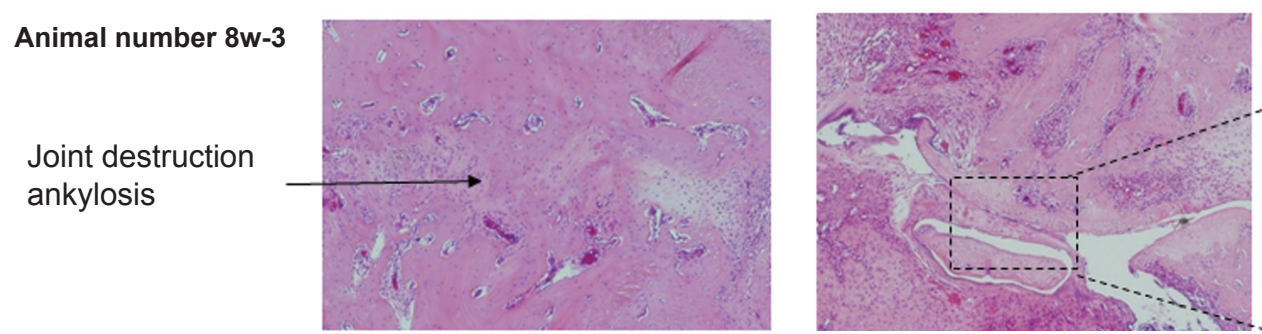

Animal number $8 w-7$

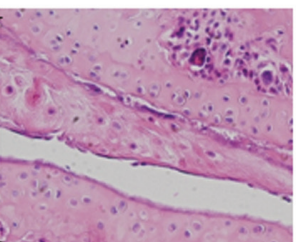

Figure 4 Representative images of the joint damage at each time point in arthritis model rats. A) After four weeks of treatment, there was a tendency in the group treated with phosphate-buffered saline (PBS) towards a more severe degree of synovitis than in the group treated with C60 (I0.0 $\mu \mathrm{M})$. B) At six weeks after immunization, intraarticular treatment with $\mathrm{C} 60$ inhibited the infiltration of inflammatory cells, synovial hyperplasia, and bone resorption by multinucleated osteoclastic cells in the ankle joints of arthritis model rats, whereas the control joints that was treated with PBS showed more severe damage. C) At the eight-week time point, all ankle joints that had been treated with PBS showed severe joint destruction and bony ankylosis. In contrast, inhibitory effects were observed following administration of C60 in the C60-treated group.

of inflammation-related cells. ROS is a messenger of the intracellular signal pathway for generation of inflammation. ${ }^{11-17}$ These results suggest that $\mathrm{C} 60$ might be used as an agent for suppressing proinflammatory cytokine production by infiltrating cells in RA synovial tissue and the resultant bone and joint destruction. It was suggested that $\mathrm{C} 60$ might be effective in the therapy and prevention of arthritis such as RA through suppression of inflammation by the cells involved.

\section{Arthritis score in the arthritic rat model}

Indeed, we have found that C60 significantly reduced the synovitis, such as synovial hyperplasia and infiltration of inflammation-related cells, and bone resorption/destruction in the adjuvant-induced arthritic rat model, suggesting that this compound has protective properties against the arthritis.

The levels of arthritis of the ankle joints were analyzed according to the arthritis score. The control group had swollen and reddened ankle joints which were aggravated with time. In contrast, the C60-treated group showed significantly lower arthritis scores at the four-week time point and at the eightweek time point compared to the control group (Figure 2). The mean scores at the six-week time point were lower in the C60 than in the control groups, although no significant difference was observed between the two groups.

\section{Pathological tissue score in the arthritic rat model}

Adjuvant-induced arthritic rats were administered C60 $(10.0 \mu \mathrm{M})$ once per week by intra-articular injection into the ankle joints during the development of arthritis. The severity of arthritis was monitored every two weeks after immunization. Concerning pathological tissue scores, the results were consistent with the arthritis scores. Although infiltration of inflammation-related cells into the synovium 
and joint destruction progressed with time in both control and C60-treated groups, the C60-treated group showed significantly lower pathological tissue scores at four weeks and later as compared to the respective control group (Figure 3).

In the control joints, at the four-week, six-week, and eight-week time points, histological features of arthritis were evident. These joints exhibited cartilage degeneration (extension of the area of surface fibrillation, chondrocyte clustering, abnormal deposition of chondrocytes and a decreased cell density with cartilage thinning), synovial hyperplasia with neoangiogenesis, infiltration of inflammation-related cells into the synovial tissue, and bone resorption/destruction by multinucleated osteoclastic cells of the subchondral bone and areas of exposed bone. As time progressed, the joints in rats that had received an intra-articular injection of PBS showed progressive joint destruction and synovitis (Figures 3,4). Eight weeks after immunization, all joints showed marked joint destruction and ankylosis (Figure 4C).

In contrast, as shown in the representative images in Figures $4 \mathrm{~A}-\mathrm{C}$, treatment of the ankle joints with C60 markedly inhibited synovitis, such as synovial hyperplasia and infiltration of inflammation-related cells, and joint destruction in the adjuvant-induced arthritic rats. After four weeks of treatment, there was a tendency in the group treated with PBS towards a more severe degree of synovitis than in the group treated with C60 (Figures 3, 4A). In particular, after the eight-week time point, all ankle joints that had been treated with PBS showed severe joint destruction and bony ankylosis. In contrast, more mild damage was observed following administration of C60 (Figure 4C).

In the present study, we have evaluated the safety and toxicity of C60 fullerene through the monitor of body weight and hair/skin condition of animal model rats. During the study period, no significant differences in the body weight and hair condition were observed between the control group and the $\mathrm{C} 60$ treated rats group. Also, we have histologically confirmed the organs in the $\mathrm{C} 60$ treated rats at eight weeks after surgery. The treatment with water-soluble C60 did not result in acute and subacute toxicity in organs such as brain, lung, liver, kidney, testis, and adrenal gland, which were obtained from all C60-treated rats (data not shown). In these organs, tissue necrosis, fibrosis, and other degenerative signs were not observed. In addition, no significant differences were observed in the serum levels of alanine aminotransferase activity during the study period in the C60-treated rats, suggesting that C60 did not incur any acute or subacute liver dysfunction in the rabbits (data not shown).
In our previous study, the effect of C60 on degeneration of articular cartilage was compared with that of sodium hyaluronate, which has lubricating, coating and joint protecting functions, in the OA rabbit model. ${ }^{38}$ The result showed that the inhibitory effect of C60 on cartilage degeneration was superior to that of sodium hyaluronate. In addition, combined treatment of C60 and hyaluronic acid showed a significant reduce of cartilage degeneration in comparison with that with $\mathrm{C} 60$ or sodium hyaluronic acid only, suggesting the therapeutic value of C60 fullerene in comparison with known agent and the potential usefulness of combined therapy of C60 with known agents. In the next study, we plan to compare the inhibitory effect of C60 fullerene with corticosteroid and/or other agents in the adjuvand arthritis rat model.

In conclusion, our findings indicate that water-soluble C60 fullerene can function as a protective agent against proinflammatory cytokine production from synovial inflammation-related cells and the resultant synovitis in vitro. Intra-articular treatment with this compound significantly reduces synovitis and joint destruction in the rat model of arthritis. These findings suggest that C60 fullerene may be useful as a therapeutic agent for arthritis.

\section{Acknowledgments}

This study was supported by grants from the Ministry of Education, Culture, Sports, Science and Technology of Japan, The Ministry of Health, Labour and Welfare of Japan. The authors report no conflicts of interest in this work.

\section{References}

1. Rooney M, Condell D, Quinlan W, et al. Analysis of the histological variation of synovitis in rheumatoid arthritis. Arthritis Rheum. 1988;31:956-963.

2. Cush JJ, Pietschmann P, Oppenheimer-Marks N, Lipsky PE. The intrinsic migratory capacity of memory $\mathrm{T}$ cells contributes to their accumulation in rheumatoid synovium. Arthritis Rheum. 1992;35:1434-1444.

3. Firestein GS. Rheumatoid synovitis and pannus. In: Klippel JH, Dieppe PA, editors. Rheumatology. London, UK: Mosby; 1998. p. 1-24.

4. Wolfe F, Michaud K. Biologic treatment of rheumatoid arthritis and the risk of malignancy: analyses from a large US observational study. Arthritis Rheum. 2007;56(9):2886-2895.

5. Tambar S, Ruderman EM. Current management of rheumatoid arthritis. Manag Care Interface. 2007;20(7):18-24.

6. Dixon WG, Symmons DP, Lunt M, Watson KD, Hyrich KL; British Society for Rheumatology Biologics Register Control Centre Consortium, Silman AJ; British Society for Rheumatology Biologics Register. Serious infection following anti-tumor necrosis factor alpha therapy in patients with rheumatoid arthritis: lessons from interpreting data from observational studies. Arthritis Rheum. 2007;56(9): 2896-2904.

7. Aletaha D, Strand V, Smolen JS, Ward MM. Treatment-related improvement in physical function varies with duration of rheumatoid arthritis: a pooled analysis of clinical trial results. Ann Rheum Dis. 2008;67(2):238-243. 
8. Genovese MC, Schiff M, Luggen M, et al. Efficacy and safety of the selective co-stimulation modulator abatacept following 2 years of treatment in patients with rheumatoid arthritis and an inadequate response to anti-TNF therapy. Ann Rheum Dis. 2008;67(4):547-554.

9. Lee YH, Rho YH, Choi SJ, Ji JD, Song GG. Association of TNF-alpha-308 G/A polymorphism with responsiveness to TNFalpha-blockers in rheumatoid arthritis: a meta-analysis. Rheumatol Int. 2006;27(2):157-161.

10. Connell L, McInnes IB. New cytokine targets in inflammatory rheumatic diseases. Best Pract Res Clin Rheumatol. 2006;20(5):865-878.

11. Vlahopoulos S, Boldogh I, Casola A, Brasier AR. Nuclear factorkappaB-dependent induction of interleukin-8 gene expression by tumor necrosis factor alpha: evidence for an antioxidant sensitive activating pathway distinct from nuclear translocation. Blood. 1999;94(6): 1878-1889.

12. Matsuzawa A, Saegusa K, Noguchi T, et al. ROS-dependent activation of the TRAF6-ASK1-p38 pathway is selectively required for TLR4-mediated innate immunity. Nat Immunol. 2005;6(6):587-592.

13. Babbar N, Casero RA Jr. Tumor necrosis factor-alpha increases reactive oxygen species by inducing spermine oxidase in human lung epithelial cells: a potential mechanism for inflammation-induced carcinogenesis. Cancer Res. 2006;66(23):11125-11130.

14. Jamaluddin M, Wang S, Boldogh I, Tian B, Brasier AR. TNFalpha-induced NF-kappaB/RelA Ser(276) phosphorylation and enhanceosome formation is mediated by an ROS-dependent PKAc pathway. Cell Signal. 2007;19(7):1419-1433.

15. Tao F, Gonzalez-Flecha B, Kobzik L. Reactive oxygen species in pulmonary inflammation by ambient particulates. Free Radic Biol Med. 2003;35(4):327-340.

16. Köhler HB, Huchzermeyer B, Martin M, De Bruin A, Meier B, Nolte I. TNF-alpha dependent NF-kappa B activation in cultured canine keratinocytes is partly mediated by reactive oxygen species. Vet Dermatol. 2001;12(3):129-137.

17. Shi MM, Godleski JJ, Paulauskis JD. Regulation of macrophage inflammatory protein-1alpha mRNA by oxidative stress. J Biol Chem. 1996;271(10):5878-5883.

18. Takayanagi H. Mechanistic insight into osteoclast differentiation in osteoimmunology. J Mol Med. 2005;83(3):170-179.

19. Sato K, Takayanagi H. Osteoclasts, rheumatoid arthritis, and osteoimmunology. Curr Opin Rheumatol. 2006;18(4):419-426.

20. Walsh MC, Kim N, Kadono Y, Rho J, Lee SY, Lorenzo J, Choi Y. Osteoimmunology: interplay between the immune system and bone metabolism. Annu Rev Immunol. 2006;24:33-63.

21. Takayanagi H. Osteoimmunology: shared mechanisms and crosstalk between the immune and bone systems. Nat Rev Immunol. 2007;7(4):292-304.

22. Alnaeeli M, Park J, Mahamed D, Penninger JM, Teng YT. Dendritic cells at the osteo-immune interface: implications for inflammation-induced bone loss. J Bone Miner Res. 2007;22(6):775-780.

23. Lean JM, Davies JT, Fuller K, et al. A crucial role for thiol antioxidants in estrogen-deficiency bone loss. J Clin Invest. 2003;112(6):915-923.

24. Ha H, Kwak HB, Lee SW, et al. Reactive oxygen species mediate RANK signaling in osteoclasts. Exp Cell Res. 2004;301(2):119-127.

25. Bai XC, Lu D, Liu AL, et al. Reactive oxygen species stimulates receptor activator of NF-kappaB ligand expression in osteoblast. J Biol Chem. 2005;280(17):17497-17506
26. Lee NK, Choi YG, Baik JY, et al. A crucial role for reactive oxygen species in RANKL-induced osteoclast differentiation. Blood. 2005;106(3):852-859.

27. Yip KH, Zheng MH, Steer JH, et al. Thapsigargin modulates osteoclastogenesis through the regulation of RANKL-induced signaling pathways and reactive oxygen species production. J Bone Miner Res. 2005;20(8):1462-1471.

28. Varanasi SS, Datta HK. Characterisation of cytosolic FK506 binding protein 12 and its role in modulating expression of $\mathrm{Cbfa} 1$ and osterix in ROS 17/2.8 cells. Bone. 2005;36(2):243-253.

29. Kim HJ, Chang EJ, Kim HM, et al. Antioxidant alpha-lipoic acid inhibits osteoclast differentiation by reducing nuclear factor-kappaB DNA binding and prevents in vivo bone resorption induced by receptor activator of nuclear factor-kappaB ligand and tumor necrosis factor-alpha. Free Radic Biol Med. 2006;40(9):1483-1493.

30. Kroto HW, Heath S, O'Brien SC, Curl RF, Smalley RE. C60: Buckminsterfullerene. Nature. 1985;318:162-163.

31. Kratschmer W, Lamb LD, Fostiropoulos K, Huffman DR. Solid C60: a new form of carbon. Nature. 1990;318:162-163.

32. Krusic PJ, Wassermann E, Keizer PN, Morton JR, Preston KF. Radical reaction of C60. Science. 1991;254:1183-1185.

33. Dugan LL, Lovett EG, Quick KL, Lotharius J, Lin TT, O’Malley KL. Fullerene-based antioxidants and neurodegenerative disorders. Parkinsonism Relat Disord. 2001;7(3):243-246.

34. Tsuchiya T, Yamakoshi YN, Miyata N. A novel promoting action of fullerene $\mathrm{C} 60$ on the chondrogenesis in rat embryonic limb bud cell culture system. Biochem Biophys Res Commun. 1995;206(3):885-894.

35. Xiao L, Takada H, Maeda K, Haramoto H, Miwa N. Antioxidant effects of water-soluble fullerene derivatives against ultraviolet ray or peroxylipid through their action of scavenging the reactive oxygen species in human skin keratinocytes. Biomed Pharmacother. 2005;59:351-358.

36. Gharbi N, Pressac M, Hadchouel M, Szwarc H, Wilson SR, Moussa F. [60]fullerene is a powerful antioxidant in vivo with no acute or subacute toxicity. Nano Lett. 2005;5:2578-2585.

37. Yudoh K, Shishido K, Murayama H, et al. Water-soluble C60 fullerene prevents degeneration of articular cartilage in osteoarthritis via down-regulation of chondrocyte catabolic activity and inhibition of cartilage degeneration during disease development. Arthritis Rheum. 2007;56(10):3307-3318.

38. Xiao L, Takada H, Gana XH, Miwa N. The water-soluble fullerene derivative 'Radical Sponge' exerts cytoprotective action against UVA irradiation but not visible-light-catalyzed cytotoxicity in human skin keratinocytes. Bioorg Med Chem Lett. 2006;16:1590-1595.

39. Mori T, Takada H, Ito S, Matsubayashi K, Miwa N, Sawaguchi T. Preclinical studies on safety of fullerene upon acute oral administration and evaluation for no mutagenesis. Toxicology. 2006;225:48-54.

40. Haruna Y, Morita Y, Yada T, Satoh M, Fox DA, Kashihara N. Fluvastatin reverses endothelial dysfunction and increased vascular oxidative stress in rat adjuvant-induced arthritis. Arthritis Rheum. 2007;56(6):1827-1835

41. Woods JM, Katschke KJ, Volin MV, et al. IL-4 adenoviral gene therapy reduces inflammation, proinflammatory cytokines, vascularization, and bony destruction in rat adjuvant-induced arthritis. J Immunol. 2001;166(2):1214-1222.

42. Haas CS, Amin MA, Allen BB, et al. Inhibition of angiogenesis by interleukin-4 gene therapy in rat adjuvant-induced arthritis. Arthritis Rheum. 2006;54(8):2402-2414.
International Journal of Nanomedicine

\section{Publish your work in this journal}

The International Journal of Nanomedicine is an international, peerreviewed journal focusing on the application of nanotechnology in diagnostics, therapeutics, and drug delivery systems throughou the biomedical field. This journal is indexed on PubMed Central,

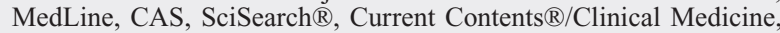

\section{Dovepress}

Journal Citation Reports/Science Edition, EMBase, Scopus and the Elsevier Bibliographic databases. The manuscript management system is completely online and includes a very quick and fair peer-review system, which is all easy to use. Visit http://www.dovepress.com/ testimonials.php to read real quotes from published authors. 